\title{
A low-protein diet supplemented with ketoacids plays a more protective role against oxidative stress of rat kidney tissue with 5/6 nephrectomy than a low-protein diet alone
}

\author{
Xiang $\mathrm{Gao}^{1}$, Jianxiang $\mathrm{Wu}^{2}$, Zheyi Dong ${ }^{1}$, Can $\mathrm{Hua}^{1}$, Huimin $\mathrm{Hu}^{1}$ and Changlin $\mathrm{Mei}^{1}{ }^{*}$ \\ ${ }^{1}$ Department of Medicine, Kidney Institute of PLA, Changzheng Hospital, Second Military Medical University, Shanghai 200003, \\ People's Republic of China \\ ${ }^{2}$ Division of Cardiology, Department of Medicine, Changzheng Hospital, Second Military Medical University, Shanghai 200003, \\ People's Republic of China \\ (Received 5 June 2009 - Revised 20 July 2009 - Accepted 13 August 2009 - First published online 2 November 2009)
}

Dietary protein restriction is one major therapy in chronic kidney disease (CKD), and ketoacids have been evaluated in CKD patients during restricted-protein diets. The objective of the present study was to compare the efficacy of a low-protein diet supplemented with ketoacids $($ LPD + KA) and a low-protein diet alone (LPD) in halting the development of renal lesions in CKD. 5/6 Nephrectomy Sprague-Dawley rats were randomly divided into three groups, and fed with either $22 \%$ protein (normal-protein diet; NPD), $6 \%$ protein (LPD) or $5 \%$ protein plus $1 \%$ ketoacids (LPD + KA) for 24 weeks. Sham-operated rats were used as controls. Each 5/6 nephrectomy group included fifteen rats and the control group included twelve rats. Proteinuria, decreased renal function, glomerular sclerosis and tubulointerstitial fibrosis were found in the remnant kidneys of the NPD group. Protein restriction ameliorated these changes, and the effect was more obvious in the LPD + KA group after 5/6 nephrectomy. Lower body weight and serum albumin levels were found in the LPD group, indicating protein malnutrition. Lipid and protein oxidative products were significantly increased in the LPD group compared with the LPD + KA group. These findings indicate that a LPD supplemented with ketoacids is more effective than a LPD alone in protecting the function of remnant kidneys from progressive injury, which may be mediated by ketoacids ameliorating protein malnutrition and oxidative stress injury in remnant kidney tissue.

\section{Ketoacids: Chronic kidney disease: Oxidative stress: Malnutrition}

Dietary protein restriction is one of the major components of therapy in chronic kidney disease (CKD) and aims to slow the progression of renal failure ${ }^{(1)}$. In addition, the metabolic effects of the ketoanalogues of amino acids (ketoacids) have been evaluated in CKD patients during restricted-protein diets $^{(2)}$. Despite the large number of studies on dietary intervention that have been performed, it is still unclear whether a low-protein diet supplemented with ketoacids is better than a low-protein diet alone in renal protection of CKD patients.

Oxidative stress is a known cause of $\mathrm{CKD}^{(3)}$. The imbalance between increased production of reactive oxygen species (ROS) and limited antioxidant capacity results in a risk of damage to organic molecules such as protein, nucleic acids and lipids ${ }^{(4)}$. In partially nephrectomised rats, protein restriction is proved to limit ROS generation ${ }^{(5)}$. However, a lowprotein diet may also result in protein malnutrition which might cause oxidative stress and render remnant kidneys more susceptible to oxidant tissue injury, as has been shown in rats $^{(6)}$. In the present study, we hypothesise that a low-protein diet supplemented with ketoacids exerts a better protective role compared with a low-protein diet in 5/6 nephrectomy rats and that oxidative stress could be a potential mechanism.

\section{Experimental methods}

\section{Experimental animal protocol}

Male Sprague-Dawley rats (weight 200-250 g) were housed in a room at a constant temperature with a $12 \mathrm{~h}$ light-dark cycle, and free access to water. The animals were randomly assigned to either the 5/6 nephrectomy group or the shamoperated control group. Each animal in the nephrectomy group underwent 5/6 nephrectomy by surgical resection of the upper and lower thirds of the left kidney followed by right nephrectomy $7 \mathrm{~d}$ later. At $7 \mathrm{~d}$ after the operation, the 5/6 nephrectomy group was then randomly divided into three groups maintained on three different diets: normal mouse chow ( $22 \%$ protein, normal-protein diet; NPD), a low-protein diet (6\% protein, LPD) or a low-protein diet supplemented with ketoacids (5\% protein and $1 \%$ ketoacids; LPD $+\mathrm{KA}$ ).

Abbreviations: CKD, chronic kidney disease; LPD, low-protein diet; LPD + KA, low-protein diet supplemented with ketoacids; NPD, normal-protein (mouse chow) diet; ROS, reactive oxygen species.

* Corresponding author: Dr Changlin Mei, fax +862163521416, email chlmei@hotmail.com 
Table 1. Primer sequences, product sizes and conditions for real-time PCR analysis

\begin{tabular}{|c|c|c|c|c|c|}
\hline & Sense primer & Antisense primer & $\begin{array}{l}\text { Product } \\
\text { size (bp) }\end{array}$ & $\begin{array}{c}\text { Annealing } \\
\text { temperature }\left({ }^{\circ} \mathrm{C}\right)\end{array}$ & $\begin{array}{l}\text { Cycle } \\
\text { number }\end{array}$ \\
\hline TGF- $\beta 1$ & 5'-GCCAGATCCTGTCCAAACTAA & 5'-TTGTTGCGGTCCACCATTA & 202 & 60 & 40 \\
\hline Fibronectin & 5'-GTGATCTACGAGGGACAGC & 5'-GCTGGTGGTGAAGTCAAAG & 76 & 59 & 40 \\
\hline Type I collagen & 5'-ATCCTGCCGATGTCGCTAT & 5'-CCACAAGCGTGCTGTAGGT & 207 & 60 & 40 \\
\hline Type III collagen & 5'-CTGGTCCTGTTGGTCCATCT & 5'-ACCTTTGTCACCTCGTGGAC & 131 & 60 & 40 \\
\hline Type IV collagen & 5'-GCCCTACGTTAGCAGATGTACC & 5'-TATAAATGGACTGGCTCGGAAT & 217 & 60 & 40 \\
\hline GAPDH & 5'-ATGCTGGTGCTGAGTATGTC & 5'-AGTTGTCATATTTCTCGTGG & 162 & 60 & 40 \\
\hline
\end{tabular}

TGF, transforming growth factor; GAPDH, glyceraldehyde-3-phosphate dehydrogenase.

Ketoacid (compound $\alpha$-ketoacid) was provided by FreseniusKabi (Wanchai, Hong Kong). Each 5/6 nephrectomy group included fifteen rats and the control group included twelve. The three diets were formulated according to the American Institute of Nutrition for Rodent Diets, AIN-93, and all had the same content of energy $(14.7 \mathrm{~kJ} / \mathrm{g})$, vitamin and mineral mix. Interventions lasted for 24 weeks. At the end of the study, six NPD rats, two LPD rats and two LPD + KA rats had died, but no controls. The $24 \mathrm{~h}$ urine samples were collected in metabolism cages. Immediately before euthanasia, blood samples were drawn from the retro-orbital sinus.

\section{Blood and urine examination}

Serum creatinine, blood urea N, serum albumin levels and $24 \mathrm{~h}$ urinary protein excretion were determined colorimetrically utilising a commercial kit (Roche, Basel, Switzerland).

\section{Renal semi-quantitative morphometry}

Remnant or control kidneys were removed, fixed in $10 \%$ buffered formalin, embedded in paraffin and sliced in $3 \mathrm{~mm}$ thick sections. These were stained by Masson's Trichrome. Morphological analyses were performed by an experienced pathologist blinded to the source of the tissue. The extent of glomerular sclerosis was assessed as described previously ${ }^{(7)}$. At least thirty glomeruli from each kidney were graded according to the following criteria: 0 , no sclerosis; 1 , less than $25 \%$ cross-sectional sclerosis; 2, 25-50\% exhibiting sclerosis; 3, 50-75\% exhibiting sclerosis; 4, over $75 \%$ cross-sectional sclerosis. The mean score per glomerulus in each kidney was determined as the sclerosis index ${ }^{(8)}$. Similarly, sections from each kidney cortex were graded for the presence of interstitial fibrosis according to the following scale: 0 , no evidence of interstitial fibrosis; 1 , less than $10 \%$ involvement; $2,10-25 \%$ involvement; $3,25-50 \%$ involvement; 4, 50-75\% involvement; 5 , more than $75 \%$ involvement ${ }^{(9)}$. The scale for each rat was reported as the mean of twenty random high-power $(\times 400)$ fields per section.

\section{Immunohistochemical staining}

The immunoperoxidase staining was performed as described previously ${ }^{(10)}$, with the following antibodies: nitrotyrosine expression was detected with monoclonal mouse anti-rat 3-nitrotyrosin (abcam, Cambridge, Cambs, UK); fibronectin was analysed with monoclonal mouse anti-rat fibronectin (Santa Cruz Biotechnology, Inc., Santa Cruz, CA, USA); and type I collagen was monoclonal mouse anti-rat type I collagen(Sigma, St Louis, MO, USA).

The intensity of glomerular staining was evaluated under $\times 400$ magnification according to the following scale: 0 , no staining; 1 , weak and spotty intraglomerular staining; 2, moderate and segmental intraglomerular staining; 3, strong and diffuse (involving more than $50 \%$ ) intraglomerular staining. Likewise, the intensity of tubulointerstitial staining in cortical areas was assessed under $\times 200$ magnification as the following scale: 0 , no staining; 1 , less than $25 \%$ involvement; 2, 25-50\% involvement; 3 , more than $50 \%$ involvement. At least twenty glomeruli and twenty randomly selected cortical tubulointerstitial areas from each sample were evaluated.

Total RNA was extracted from renal cortex tissue using an RNase mini kit (Invitrogen Corp., Carlsbad, CA, USA). Primers for glyceraldehyde-3-phosphate dehydrogenase, transforming growth factor- $\beta 1$, fibronectin, and types I, III and IV collagen were designed and synthesised based on published sequences of these genes ${ }^{(11)}$. Real-time PCR was performed using SYBR Green PCR Master Mix (Toyobo, Osaka, Japan) and the Rotor-Gene-3000A Realtime PCR System (Corbett, Sydney, Australia), according to the manufacturers' protocols. Sequences of the rat primer pairs and the original clones are listed in Table 1.

\section{Oxyblot analysis}

To assess the formation of protein carbonyl groups, the oxyblot protein oxidation detection kit (Chemicon International,

Table 2. Metabolic data

(Mean values and standard deviations)

\begin{tabular}{|c|c|c|c|c|}
\hline \multirow[b]{2}{*}{ Group§ } & \multicolumn{2}{|c|}{ Body weight (g) } & \multicolumn{2}{|c|}{$\begin{array}{l}\text { Kidney weight: } \\
\text { body weight }(\mathrm{mg} / \mathrm{g})\end{array}$} \\
\hline & Mean & SD & Mean & SD \\
\hline Control & $635.0^{* *}$ & $66 \cdot 7$ & 2.79 & 0.22 \\
\hline NPD & $665 \cdot 4^{\star \star}$ & $78 \cdot 2$ & $3.77 \neq \ddagger$ & 0.80 \\
\hline LPD & $489.6+\dagger$ & $43 \cdot 3$ & $2 \cdot 77$ & 0.17 \\
\hline $\mathrm{LPD}+\mathrm{KA}$ & $560 \cdot 9$ & $57 \cdot 2$ & $2 \cdot 72$ & 0.31 \\
\hline
\end{tabular}

NPD, normal-protein (mouse chow) diet; LPD, low-protein diet; LPD + KA, low-protein diet supplemented with ketoacids.

** Mean value was significantly different from those of the LPD and LPD $+K$ groups $(P<0.01)$.

†† Mean value was significantly different from that of the LPD + KA group $(P<0.01)$.

$\ddagger \ddagger$ Mean value was significantly different from those of the other three groups $(P<0.01)$.

$\S$ For details of the diets, see the Experimental methods section. 
Table 3. Biochemical data from chronic kidney disease and control rats (Mean values and standard deviations)

\begin{tabular}{|c|c|c|c|c|c|c|c|c|}
\hline \multirow[b]{2}{*}{ Group§ } & \multicolumn{2}{|c|}{$\begin{array}{l}\text { Serum albumin } \\
(\mathrm{g} / \mathrm{l})\end{array}$} & \multicolumn{2}{|c|}{$\begin{array}{l}\text { Blood urea N } \\
(\mathrm{mmol} / \mathrm{l})\end{array}$} & \multicolumn{2}{|c|}{$\begin{array}{l}\text { Serum creatinine } \\
\qquad(\mu \mathrm{mol} / \mathrm{l})\end{array}$} & \multicolumn{2}{|c|}{$\begin{array}{l}\text { Urinary protein } \\
(\mathrm{mg} / 24 \mathrm{~h})\end{array}$} \\
\hline & Mean & SD & Mean & SD & Mean & SD & Mean & SD \\
\hline Control & $50.58^{*}$ & 1.93 & $7.98+\dagger$ & 0.68 & $30 \cdot 30 \neq \ddagger$ & 2.50 & $7.47 \dagger \dagger$ & 2.42 \\
\hline NPD & $45 \cdot 86$ & 8.07 & $18 \cdot 18 \neq \ddagger$ & 8.89 & 67.63 & 27.95 & $51.79 \neq \ddagger$ & $32 \cdot 30$ \\
\hline LPD & 46.93 & 4.09 & $7.75+\dagger$ & 1.38 & $68 \cdot 38$ & 9.35 & $8.48+\dagger$ & 8.52 \\
\hline LPD $+K A$ & $51 \cdot 88^{\star}$ & $2 \cdot 28$ & $5 \cdot 81$ & 0.65 & 62.90 & 2.90 & $4 \cdot 10$ & 1.33 \\
\hline
\end{tabular}

NPD, normal-protein (mouse chow) diet; LPD, low-protein diet; LPD + KA, low-protein diet supplemented with ketoacids. * Mean value was significantly different from those of the NPD and LPD groups $(P<0.05)$.

t† Mean value was significantly different from that of the LPD + KA group $(P<0.01)$.

$\ddagger \ddagger$ Mean value was significantly different from those of the other three groups $(P<0.01)$

$\S$ For details of the diets, see the Experimental methods section.

Temecula, CA, USA) was used according to the manufacturer's detailed protocol. A $5 \mu \mathrm{l}$ protein sample $(20 \mu \mathrm{g})$ was added with $5 \mu \mathrm{l}$ of $12 \%$ SDS and $10 \mu \mathrm{l}$ of $1 \times$ dinitrophenylhydrazine solution into a tube. Instead of the dinitrophenylhydrazine solution, $10 \mu l$ of $1 \times$ derivatisationcontrol solution served as the negative control. Tubes were incubated at room temperature for $15 \mathrm{~min}$. Neutralisation solution $(7.5 \mu \mathrm{l})$ was added to each tube, and one mixed sample per lane was loaded onto $4-12 \%$ Tris-glycine gels with equal volumes of SDS sample buffer. Following electrophoresis and transfer to polyvinylidene difluoride membranes, the membranes were blocked by incubation with $1 \%$ bovine serum albumin for $1 \mathrm{~h}$ and then incubated for $1 \mathrm{~h}$ at room temperature with rabbit anti-dinitrophenol (1:150). Blots were subsequently incubated for $1 \mathrm{~h}$ with anti-rabbit immunoglobulins (at 1:300) and developed by an enhanced chemiluminescence detection system (Santa Cruz Biotechnology, Inc.). Proteins that underwent oxidative modification were identified as a band in the derivatised sample, but not in the negative control. Levels of oxidatively modified proteins were quantified and expressed as fold increase $v$. normal controls via measurement of optical density using the National Institutes of Health (NIH) Image analysis software (Research Services Branch, NIH, Bethesda, MD, USA).

\section{Determination of renal malondialdehyde and superoxide dismutase activity}

A part of the homogenate was used for the determination of tissue content of malondialdehyde, and it was determined
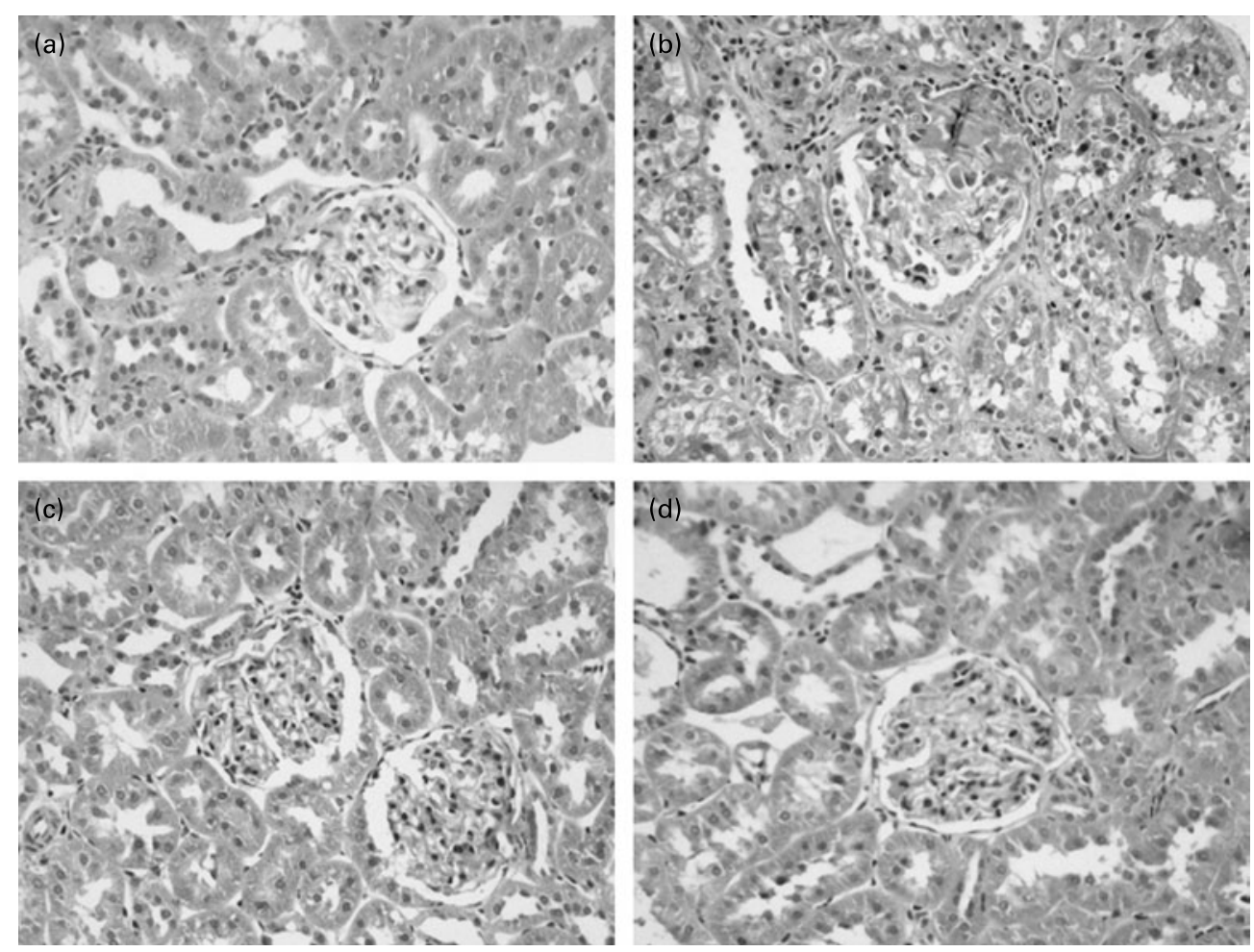

Fig. 1. Masson staining of renal tissue of control rats on a normal-protein (mouse chow) diet (NPD) (a) and 5/6 nephrectomy rats on the NPD (b), a low-protein diet (LPD) (c) and the LPD supplemented with ketoacids (d). Magnification $\times 400$. 
Table 4. Semi-quantitative analyses of renal Masson staining and immunohistochemical staining (Mean values and standard deviations)

\begin{tabular}{|c|c|c|c|c|c|c|c|c|c|c|}
\hline \multirow[b]{2}{*}{ Groupł } & \multicolumn{2}{|c|}{$\begin{array}{l}\text { Glomerular } \\
\text { sclerosis index }\end{array}$} & \multicolumn{2}{|c|}{$\begin{array}{l}\text { Tubulointerstitial } \\
\text { fibrosis score }\end{array}$} & \multicolumn{2}{|c|}{$\begin{array}{l}\text { Glomerular } \\
\text { fibronectin } \\
\text { staining score }\end{array}$} & \multicolumn{2}{|c|}{$\begin{array}{l}\text { Tubulointerstitial } \\
\text { fibronectin } \\
\text { staining score }\end{array}$} & \multicolumn{2}{|c|}{$\begin{array}{l}\text { Tubulointerstitial } \\
\text { collagen I } \\
\text { staining score }\end{array}$} \\
\hline & Mean & SD & Mean & SD & Mean & SD & Mean & SD & Mean & SD \\
\hline Control & 0.03 & 0.05 & 0.04 & 0.05 & 0.07 & 0.06 & 0.08 & 0.08 & 0.04 & 0.06 \\
\hline NPD & $0 \cdot 84^{\star \star}$ & 0.14 & $2 \cdot 97^{\star \star}$ & 1.17 & $0.84^{\star \star}$ & 0.05 & $3 \cdot 61^{\star \star}$ & 1.11 & $2 \cdot 96^{\star \star}$ & $1 \cdot 10$ \\
\hline LPD & $0.46 \dagger \dagger$ & 0.25 & $0.65 \uparrow \dagger$ & 0.42 & $0.42 \dagger \dagger$ & 0.13 & $0.73+\dagger$ & 0.29 & $0.71 \dagger \dagger$ & 0.36 \\
\hline $\mathrm{LPD}+\mathrm{KA}$ & 0.16 & 0.04 & 0.09 & 0.06 & $0 \cdot 16$ & 0.06 & 0.14 & 0.07 & 0.23 & 0.11 \\
\hline
\end{tabular}

NPD, normal-protein (mouse chow) diet; LPD, low-protein diet; LPD + KA, low-protein diet supplemented with ketoacids.

${ }^{\star \star}$ Mean value was significantly different from those of the control, LPD and LPD + KA groups $(P<0.01)$.

$\dagger+$ Mean value was significantly different from those of the control and LPD + KA groups $(P<0.01)$.

$\ddagger$ For details of the diets, see the Experimental methods section.

according to the method of Buege \& Aust ${ }^{(12)}$. The results were expressed as $\mathrm{nmol} / \mathrm{mg}$ protein. The other part of the homogenate was centrifuged at $10000 \mathrm{~g}$ for $15 \mathrm{~min}$ at $4^{\circ} \mathrm{C}$. The supernatant fraction was used for determination of tissue superoxide dismutase activity. $\mathrm{Cu}-\mathrm{Zn}$ superoxide dismutase activity was measured kinetically by the method of Sun et al. ${ }^{(13)}$. The activity was expressed as $\mathrm{U} / \mathrm{mg}$ protein.

\section{Statistical analyses}

Statistical significance was determined by ANOVA using StatView 4.0 (Abacus Concepts, Inc., Piscacatway, NJ, USA). Differences with $P<0.05$ were considered statistically significant.

\section{Ethical statement}

Animal usage and all the experimental procedures were approved by Ethics Committees of the Second Military Medical University and followed the Guide for the Care and Use of Laboratory Animals of the National Research Council.

\section{Results}

\section{Body weight and kidney weight}

Among the 5/6 nephrectomy groups, body weight was heaviest in the NPD group, which was not statistically different from that of the control, and least in the LPD group. The weight of the remnant kidney, corrected for body weight, was greatest in the NPD group and other groups had no statistical differences (Table 2).

\section{Proteinuria, serum albumin and renal function}

Serum albumin in the NPD and LPD groups was lower than that in the LPD + KA and control groups. Blood urea N and urinary protein excretion, which were highest in the NPD group, were significantly reduced by protein restriction; the LPD + KA group had the lowest values. 5/6 Nephrectomy also increased serum creatinine values, but dietary intervention did not make much of a difference (Table 3). Based on the present experiment and Meireles et al. ${ }^{(14)}$, who also found a lack of serum creatinine difference after dietary treatment, we consider that serum creatinine is maybe not a sensitive parameter of remnant kidney function in protein diet studies.

\section{Renal tissue damage}

In the control group, no histologic abnormalities of the kidneys were observed at the light microscopic level (Fig. 1(a)). In the 5/6 nephrectomy groups, glomerulosclerosis and interstitial fibrosis progressed, especially in the NPD group (Fig. 1(b)-(d)). Compared with the LPD group, the LPD + KA group showed more decrease in the glomerulosclerosis index and interstitial fibrosis score (Table 4). To characterise further the histologic injury, type I collagen and fibronectin immunohistochemical studies were performed in the four groups. A marked increased expression of type I collagen was observed in the interstitial expansion of the NPD group, and fibronectin was notably expressed in the glomerular and tubular basement membrane. The decrease in type I collagen and fibronectin immunostaining was also more prominent in the LPD + KA group compared with the LPD group (Fig. 2 and Table 4).

\section{Expression of fibrosis-related genes}

Since we found differences in the renal tissue damage in different dietary intervention groups, we further studied the expression of fibrosis-related genes by real-time PCR. The gene expression of transforming growth factor- $\beta 1$, type I collagen, type III collagen and fibronectin was significantly increased in the kidneys of the NPD group. Weak expression was detected in the LPD + KA and control groups with no significant differences, and the intensity was decreased compared with the LPD group (Fig. 3(a)-(d)). The gene expression of type IV collagen, however, did not reach significant difference between the LPD and LPD + KA groups (Fig. 3(e)).

\section{Level of oxidation}

Since oxidative stress plays a key role in the progression of CKD, we hypothesised that oxidative stress caused the differences between the LPD and LPD + KA groups in renal tissue damage. Increased oxidative stress is known to 
cause damage to membrane lipids, and thus lipid peroxidation in tissues could cause renal injury. Malondialdehyde, a lipid peroxidation product, was measured and found to be increased in the NPD and LPD groups, while the
LPD + KA and control groups had no significant difference (Table 5).

Protein nitrosylation is considered to be a footprint of NO-ROS-protein interaction ${ }^{(15)}$. ROS inactivate $\mathrm{NO}$ and,
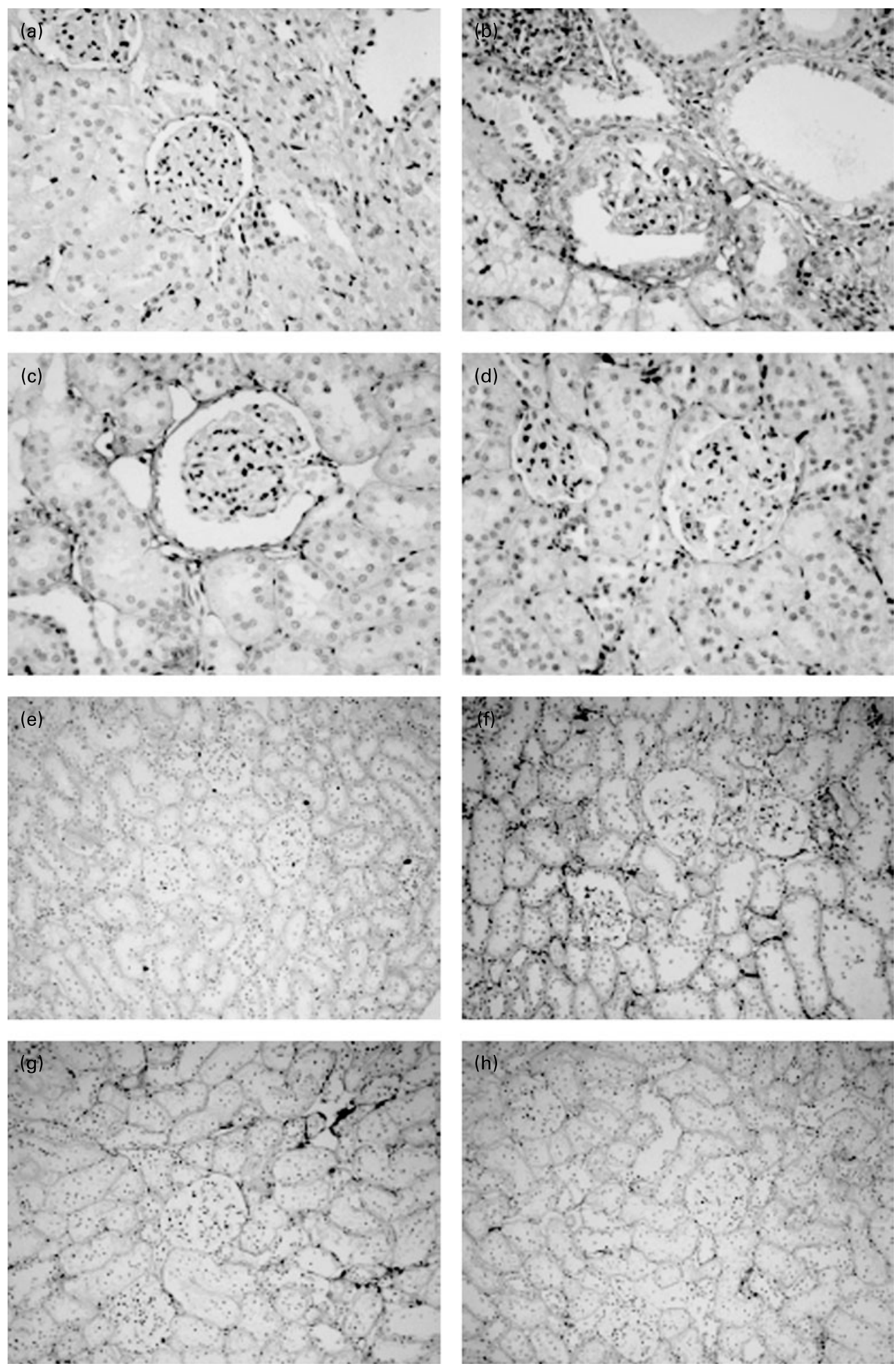

Fig. 2. Immunohistochemical micrographs of fibronectin staining in kidneys of control rats on a normal-protein (mouse chow) diet (NPD) (a) and 5/6 nephrectomy rats on the NPD (b), a low-protein diet (LPD) (c) and the LPD supplemented with ketoacids (LPD + KA) (d). Immunohistochemical micrographs of type I collagen staining of kidneys of control rats on the NPD (e) and 5/6 nephrectomy rats on the NPD (f), the LPD (g) and the LPD +KA (h). Magnification: (a) to (d) $\times 400 ;(e)$ to (h) $\times 200$. 

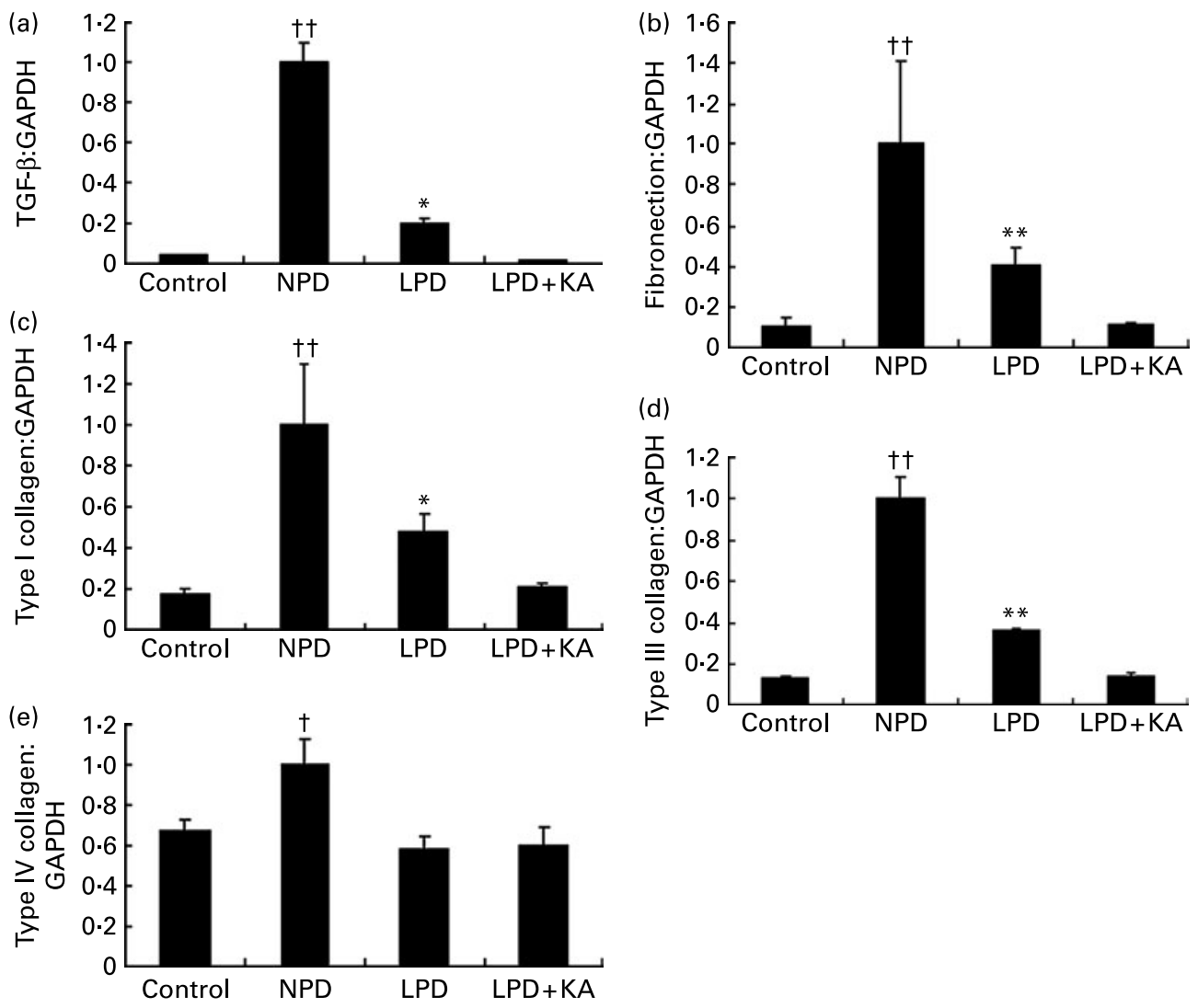

Fig. 3. Renal mRNA expressions of transforming growth factor (TGF)- $\beta$ (a), fibronectin (b), type I collagen (c), type III collagen (d) and type IV collagen (e) in control rats on a normal-protein (mouse chow) diet (NPD) and 5/6 nephrectomy rats on the NPD, a low-protein diet (LPD) and the LPD supplemented with ketoacids $(\mathrm{LPD}+\mathrm{KA})$. The relative expression ratios for each mRNA in relation to glyceraldehyde-3-phosphate dehydrogenase (GAPDH) mRNA were determined. Values are means, with standard errors represented by vertical bars. Mean value was significantly different from those of the control and LPD + KA groups: ${ }^{\star} P<0.05$, ${ }^{\star *} P<0.01$. Mean value was significantly different from those of the control, LPD and LPD + KA groups: $\dagger P<0.05, \dagger \dagger P<0.01$.

in the process, produce highly reactive and cytotoxic products, such as peroxynitrite. Peroxynitrite reacts with the tyrosine residues in protein molecules to produce nitrotyrosine. To determine the amount of peroxynitrite, we evaluated the presence of nitrotyrosilated proteins. As observed in Fig. 4, nitrotyrosine reactivity was present in almost all tubular structures and was increased in the kidneys of the NPD rats. LPD and LPD + KA therapy reduced nitrotyrosine abundance in kidneys, with the LPD + KA being the more effective.

Carbonyl formation is an important detectable marker of the oxidation status of proteins. The oxyblot technique detects protein carbonyl groups formed by ROS-mediated oxidation of some amino acid side-chains ${ }^{(16)}$. The density of the protein band in the oxyblot analysis shown in Fig. 5 demonstrates that the CKD model induced a modification of protein in the renal cortex of rats due to carbonyl formation. LPD treatment reduced some change whereas the LPD + KA reduced much more, and there was no significant difference in protein carbonyl formation between the LPD + KA group and the control group.

The superoxide dismutases are a family of enzymes that protect tissues from damage by catalysing the conversion of the superoxide anion radical to $\mathrm{H}_{2} \mathrm{O}_{2}$ and $\mathrm{O}_{2}$. The level of superoxide dismutase activity was measured but there was no significant difference of this enzyme between the four groups (Table 5).

\section{Discussion}

The present study demonstrated that a low-protein diet plus ketoacids played a more protective role in the remnant kidney model compared with a low-protein diet alone. The level of urinary protein in the LPD + KA group after $5 / 6$ nephrectomy was lower than that in the LPD group.

Table 5. Renal cortex malondialdehyde (MDA) and superoxide dismutase (SOD) levels

(Mean values and standard deviations)

\begin{tabular}{lllllr}
\hline & \multicolumn{2}{c}{$\begin{array}{c}\text { MDA } \\
\text { (nmol/mg protein) }\end{array}$} & & \multicolumn{2}{c}{$\begin{array}{c}\text { SOD } \\
\text { (U/mg protein) }\end{array}$} \\
\cline { 2 - 3 } Group $\ddagger$ & Mean & SD & & Mean & SD \\
\hline Control & 0.80 & 0.11 & & 167.1 & 33.65 \\
NPD & $1.28^{\star}$ & 0.33 & & 174.6 & 35.35 \\
LPD & $1.05 \dagger$ & 0.05 & & 181.8 & 32.50 \\
LPD + KA & 0.85 & 0.09 & & 162.5 & 24.50
\end{tabular}

NPD, normal-protein (mouse chow) diet; LPD, low-protein diet; LPD + KA, low-protein diet supplemented with ketoacids.

* Mean value was significantly different from those of the control, LPD and LPD + KA groups $(P<0.05)$.

$\dagger$ Mean value was significantly different from those of the control and $\mathrm{LPD}+\mathrm{KA}$ groups $(P<0.05)$.

$\ddagger$ For details of the diets, see the Experimental methods section. 

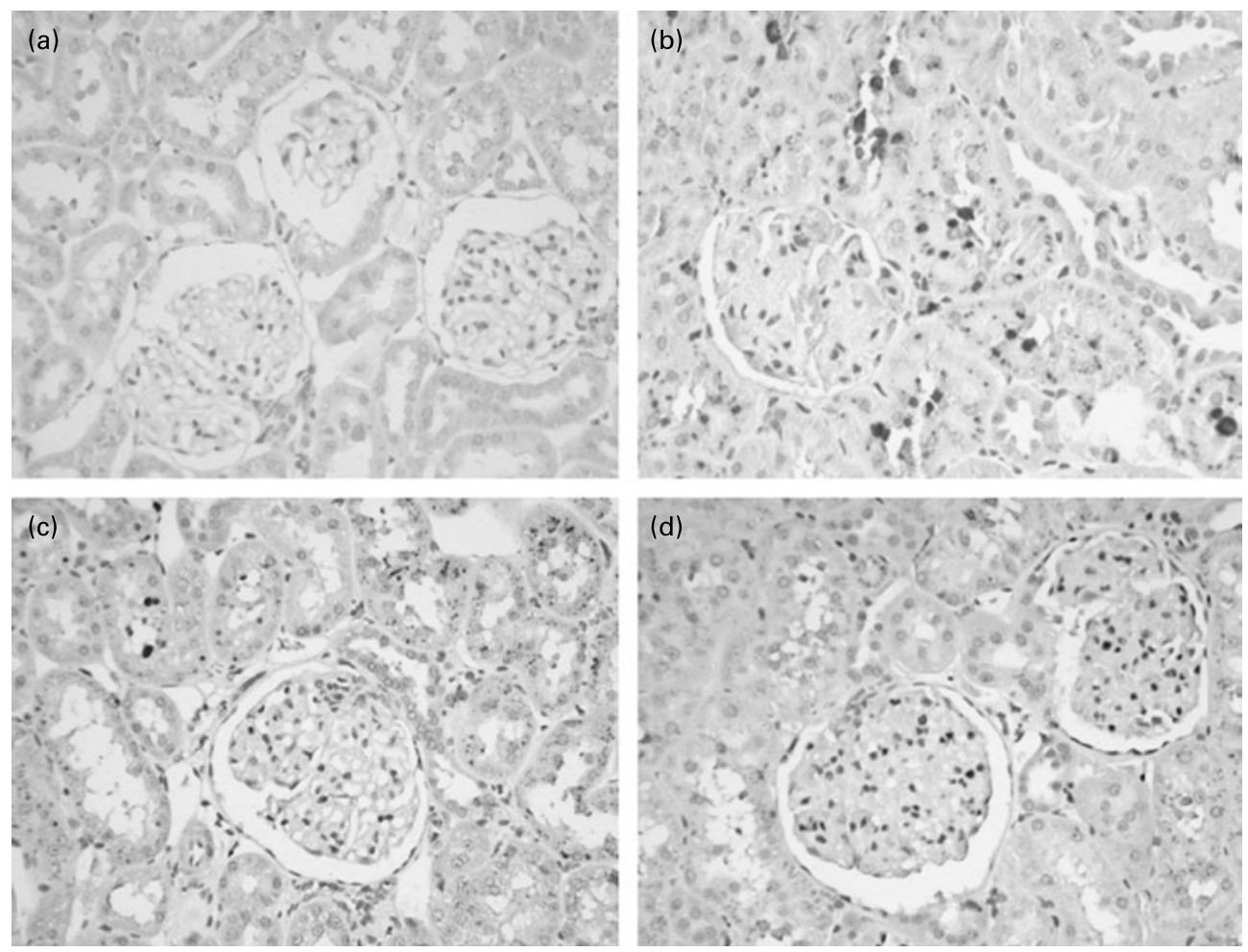

Fig. 4. Immunohistochemical staining of nitrotyrosine in tubular compartments of the renal cortex in control rats on a normal-protein (mouse chow) diet (NPD) (a) and 5/6 nephrectomy rats on the NPD (b), a low-protein diet (LPD) (c) and the LPD supplemented with ketoacids (d). Magnification $\times 400$.

Amelioration of glomerulosclerosis and interstitial fibrosis with accumulation of type I collagen and fibronectin was more prominent in the LPD + KA treatment group than the LPD group. Fibrosis-related mRNA levels such as transforming growth factor- $\beta 1$, type I collagen, type III collagen and fibronectin also decreased more in the LPD + KA group than in the LPD group. Since ketoacids reduced the accumulation of $\mathrm{N}$ waste products by decreasing the exogenous $\mathrm{N}$ supply and enhancing the reutilisation of stored $\mathrm{N}$, blood urea $\mathrm{N}$ level was also lower in the ketoacid group.

Oxidative stress could contribute to the differences between the LPD and LPD + KA groups. CKD can be exacerbated by oxidative stress which promotes production of reactive carbonyl compounds and lipoperoxides leading to the accumulation of advanced glycation and lipoxidation endproducts. Besides, ROS avidly react with NO, producing cytotoxic reactive nitrogen species capable of nitrating proteins and damaging other molecules ${ }^{(16)}$. It has been proved that oxidative stress plays an important role in the development and progression of sclerosis and fibrosis in the remnant kidney model of chronic renal failure ${ }^{(3,17)}$. Dietary protein intake is an important determinant of renal injury with CKD and dietary protein loading has a detrimental effect on proteinuria and histological damage after renal ablation ${ }^{(5)}$. It has been proved that a low-protein diet, with or without ketoacids, has an antioxidant effect in CKD humans and animals $^{(5,18-20)}$, but no one so far has compared the effects between a low-protein diet with and without ketoacids. During the present study, we found oxidative stress levels in renal cortex tissue were lower when supplemented with ketoacids compared with a low-protein diet alone.
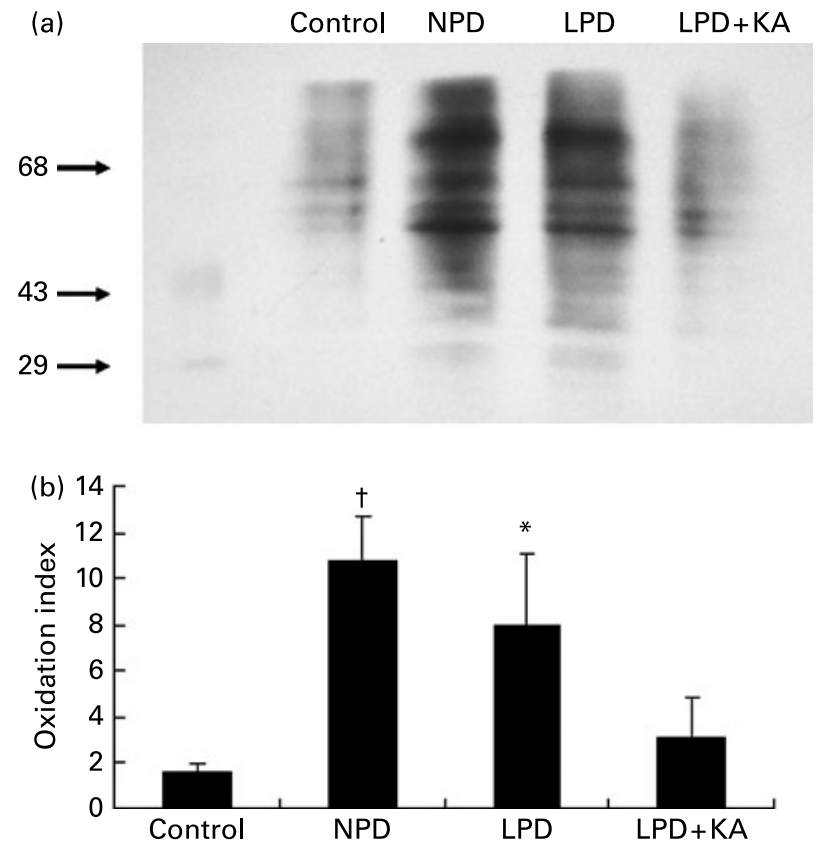

Fig. 5. Immunoblot analysis of protein carbonyl groups (markers of oxidatively modified proteins) in the renal cortex of control rats on a normal-protein (mouse chow) diet (NPD) and 5/6 nephrectomy rats on the NPD, a lowprotein diet (LPD) and the LPD supplemented with ketoacids (LPD + KA). (a) Representative immunoblot. (b) Densitometric values of the oxyblot bands. Values are means, with standard deviations represented by vertical bars. * Mean value was significantly different from those of the control and LPD + KA groups $(P<0.05)$. † Mean value was significantly different from those of the control, LPD and LPD + KA groups $(P<0.05)$. 
We measured malondialdehyde, a secondary product of lipid peroxidation, the nitrosylation stain which detects reactive nitrogen species capable of nitrating proteins and oxyblot which measures reactive carbonyl compounds, and they were all significantly reduced in the LPD + KA group compared with the LPD group. No changes in superoxide dismutase were observed in all groups. This was confirmed to by Peuchant et al. who found antioxidant enzyme activities to be similar in control and CKD individuals before and after a low-protein diet ${ }^{(19)}$, and they suspected that antioxidant enzyme activity was not modified by protein restriction.

In the present study, we found low serum albumin in the LPD group, which has proved to have an association with nutritional status ${ }^{(18)}$. Significantly decreased body weight in the LPD group also proved that dietary protein restriction impaired nutritional responses. Protein malnutrition has been reported to cause oxidative stress in extrarenal tissues by changing antioxidant enzyme activity and/or antioxidant compounds in human subjects and rats ${ }^{(6,21-23)}$. The present renal oxidative data indicated that protein malnutrition increased oxidative damage to lipids and proteins which had been confirmed by the brain study ${ }^{(23)}$. Lipid peroxidation affects membrane integrity and stability; therefore, cell membranes from malnourished animals, already altered under basal conditions, may be more sensitive when exposed to oxidative alterations. Oxidative damage to proteins may be associated with numerous alterations in mitochondrial dysfunction and the mechanism needs more in-depth study ${ }^{(23)}$. Therefore, the increased oxidative stress level caused by protein malnutrition impaired the glomerular filtration barrier and gave rise to increased rates of urinary protein excretion $^{(24)}$. This explains why the LPD group had higher urinary protein excretion and why the LPD played less of a protective role in glomerulosclerosis and interstitial fibrosis compared with the LPD + KA.

Besides, ameliorating malnutrition may not be the only reason for supplementing with ketoacids. Salahudeen et al. ${ }^{(25)}$ suggested that ketoacids effectively scavenged $\mathrm{H}_{2} \mathrm{O}_{2}$, and suppressed $\mathrm{H}_{2} \mathrm{O}_{2}$-induced renal lipid peroxidation in vitro and in vivo, which indicated that ketoacids themselves may have an antioxidant effect to lessen renal injury.

In conclusion, the present study indicates that a lowprotein diet supplemented with ketoacids plays a more renal-protective role than a low-protein diet alone in the $5 / 6$ nephrectomy rat model. The effect may be mediated by ketoacids ameliorating protein malnutrition and oxidative stress injury in remnant kidney tissue, and a low-protein diet supplemented with ketoacids could be a better therapeutic strategy for CKD patients. More studies are necessary to determine the exact mechanism of ketoacids slowing CKD progression.

\section{Acknowledgements}

We gratefully thank Mr Jun Wu, Mr Houan Cai, Mr Zhenhao Hua, Mr Ye Lin for their technical assistance. The present study was supported by Shanghai Leading Academic Discipline Project (B902), Major Projects of Shanghai Technology and Science Committee (Study of Diagnosis and Treatment of Chronic Kidney Diseases, 08dz1900600), and by a research grant from Ketosteril Research Award (2008).
X. G. and J. W. participated in the experimental design and writing the manuscript; Z. D. participated in experimental design; C. H. was responsible for the histopathological study; H. H. conducted the statistical analysis; C. M. laid down the original design of the experiments, supervised experimental work and wrote the manuscript.

We declare that there is no conflict of interest in the present paper.

\section{References}

1. Fouque D, Wang P, Laville M, et al. (2000) Low protein diets delay end-stage renal disease in non-diabetic adults with chronic renal failure. Nephrol Dial Transplant 15, 1986-1992.

2. Bernhard J, Beaufrère B, Laville M, et al. (2001) Adaptive response to a low-protein diet in predialysis chronic renal failure patients. J Am Soc Nephrol 12, 1249-1254.

3. Kobayashi M, Sugiyama H, Wang DH, et al. (2005) Catalase deficiency renders remnant kidneys more susceptible to oxidant tissue injury and renal fibrosis in mice. Kidney Int $\mathbf{6 8}$, 1018-1031.

4. Sener G, Paskaloğlu K, Satiroglu H, et al. (2004) L-Carnitine ameliorates oxidative damage due to chronic renal failure in rats. J Cardiovasc Pharmacol 43, 698-705.

5. Nankivell BJ, Tay YC, Boadle RA, et al. (1994) Dietary protein alters tubular iron accumulation after partial nephrectomy. Kidney Int 45, 1006-1013.

6. Himmelfarb J (2004) Linking oxidative stress and inflammation in kidney disease: which is the chicken and which is the egg? Semin Dial 17, 449-454.

7. Raij L, Azar S \& Keane W (1984) Mesangial immune injury, hypertension, and progressive glomerular damage in Dahl rats. Kidney Int 26, 137-143.

8. Miyazaki T, Aoyama I, Ise M, et al. (2000) An oral sorbent reduces overload of indoxyl sulphate and gene expression of TGF- $\beta 1$ in uraemic rat kidneys. Nephrol Dial Transplant 15, 1773-1781.

9. Ots M, Mackenzie HS, Troy JL, et al. (1998) Effects of combination therapy with enalapril and losartan on the rate of progression of renal injury in rats with 5/6 renal mass ablation. J Am Soc Nephrol 9, 224-230.

10. Taal MW, Chertow GM, Rennke HG, et al. (2001) Mechanisms underlying renoprotection during renin-angiotensin system blockade. Am J Physiol Renal Physiol 280, 343-355.

11. Taal MW, Zandi-Nejad K, Weening B, et al. (2000) Proinflammatory gene expression and macrophage recruitment in the rat remnant kidney. Kidney Int 58, 1664-1676.

12. Buege JA \& Aust SD (1978) Microsomal lipid peroxidation. Methods Enzymol 52, 302-310.

13. Sun Y, Oberley LW \& Li Y (1988) A simple method for clinical assay of superoxide dismutase. Clin Chem 34, 497-500.

14. Meireles CL, Price SR, Pereira AM, et al. (1999) Nutrition and chronic renal failure in rats: what is an optimal dietary protein? J Am Soc Nephrol 10, 2367-2373.

15. Halliwell B (1997) What nitrates tyrosine? Is nitrotyrosine specific as a biomarker of peroxynitrite formation in vivo? FEBS Lett 411, 157-160.

16. Aksenov MY, Aksenova MV, Butterfield DA, et al. (2001) Protein oxidation in the brain in Alzheimer's disease. Neuroscience 103, 373-383.

17. Nosratola D, Zhenmin N, Fariba O, et al. (2002) Enhanced nitric oxide inactivation and protein nitration by reactive oxygen species in renal insufficiency. Hypertension 39, 135-141. 
18. Stenvinkel P, Heimbürger O, Tuck CH, et al. (1998) Apo(a)isoform size, nutritional status and inflammatory markers in chronic renal failure. Kidney Int 53, 1336-1342.

19. Peuchant E, Delmas-Beauvieux MC, Dubourg L, et al. (1997) Antioxidant effects of a supplemented very low protein diet in chronic renal failure. Free Radic Biol Med 22, 313-320.

20. Bergesio F, Monzani G, Guasparini A, et al. (2005) Cardiovascular risk factors in severe chronic renal failure: the role of dietary treatment. Clin Nephrol 64, 103-112.

21. Tatli MM, Vural H, Koc A, et al. (2000) Altered anti-oxidant status and increased lipid peroxidation in marasmic children. Pediatr Int 42, 289-292.
22. Feoli AM, Siqueira IR, Almeida L, et al. (2006) Effects of protein malnutrition on oxidative status in rat brain. Nutrition 22, 160-165.

23. Rana S, Sodhi CP, Mehta S, et al. (1996) Protein-energy malnutrition and oxidative injury in growing rats. Hum Exp Toxicol 15, 810-814.

24. Yoshioka T, Ichikawa I \& Fogo A (1991) Reactive oxygen metabolites cause massive, reversible proteinuria and glomerular sieving defect without apparent ultrastructural abnormality. J Am Soc Nephrol 2, 902-912.

25. Salahudeen AK, Clark EC \& Nath KA (1991) Hydrogen peroxide-induced renal injury. A protective role for pyruvate in vitro and in vivo. J Clin Invest 88, 1886-1893. 